\title{
Randomized Controlled Study of Intravenous Regional Anaesthesia for Forearm \& Hand Surgery: Comparison of Lignocaine, Lignocaine with Ketamine \& Lignocaine with Dexmedetomidine
}

\author{
Dr. Palak P Sheth ${ }^{1}$, Dr. Viral Shah ${ }^{2}$, Dr. Bhavna Soni ${ }^{3}$ \\ ${ }^{1} 2^{\text {nd }}$ Year Resident, MD Anesthesia, Department of Anesthesiology, SMIMER Hospital, Umarwada, Surat, India \\ ${ }^{1} 3^{\text {rd }}$ Year Resident, MD Anesthesia, Department of Anesthesiology, SMIMER Hospital, Umarwada, Surat, India \\ ${ }^{3}$ Associate Professor, Department of Anesthesiology, SMIMER Hospital, Umarwada, Surat, India
}

Intravenous Regional Anaesthesia (IVRA) for Forearm and Hand Surgery: Comparison of Lignocine, Lignocaine with Ketamine and Lignocaine with Dexmedetomidine

\begin{abstract}
Aims \& Objectives: To evaluate the effect of Dexmedetomidine \& Ketamine as an adjuvant to Lignocaine hydrochloride $0.5 \% 40 \mathrm{ml}$ in IVRA and to assess quality of anaesthesia, postoperative analgesia and side effects for hand or forearm surgery. Material \& Method: Ninety patients were randomly assigned to three groups to receive IVRA for hand and forearm surgery: $40 \mathrm{ml}$ of 0.5\% Lignocaine and either $1 \mathrm{ml}$ of isotonic saline (Group-L) or 0.5mg/kg Ketamine (Group-LK) or 1mcg/kg Dexmedetomidine (Group-LD). Sensory blockade by pin prick method, tourniquet pain by VAS, and sedation by Ramsay score, time to first analgesic, quality of anaesthesia by patient satisfaction score and hemodynamic parameters were assessed. Results and Summary: Sensory and motor block onset time (P < 0.001) was faster in Group LK compared to Group LD and group L but duration of analgesia (p<0.001) and sedation (p>0.05) was longer in Group LD with better patient satisfaction. Conclusion: Onset of sensory (78sec) and motor block (8min) was faster with group LK in IVRA. Both adjuvants prolonged the analgesic effect of Lignocaine in IVRA but it was more with Dexmeditomidine (169min). Patients remained more comfortable and sedated with Dexmeditomidine. Thus in IVRA, addition of Dexmedetomidine or Ketamine to Lignocaine improves quality of anaesthesia and postoperative analgesia without significant side effects.
\end{abstract}

Keywords: Upper limb surgeries, IVRA, Ketamine, Lignocaine Hcl, Dexmedetomidine.

\section{Introduction}

Forearm and wrist surgeries are common surgical procedures that can be successfully performed under different mode of anaesthesia like general anaesthesia, peripheral nerve block or intravenous regional anaesthesia (IVRA)

IVRA, a popular technique is simple to administer, reliable, cost effective \& ideal for short operative procedures on the extremities performed on an ambulatory basis ${ }^{10}$. Intravenous regional anesthesia (IVRA) was first described by August Bier in 1908. It is a safe \& effective way to provide anesthesia for limb surgery, with success rate between $94 \%$ to $98 \%{ }^{18}$. The patients remain awake throughout the operative procedure \& vitals remain stable. Disadvantages of IVRA include concerns about local anaesthetic toxicity, slow onset, tourniquet pain \& minimal post operative pain relief $^{10}$, expected to last less than $120 \mathrm{~min}^{27}$ and it does not provide effective postoperative analgesia.

So to improve quality of anaesthesia and to prolong post operative analgesia, various analgesics have been administered concomitantly with the local anaesthetic in IVRA $^{29}$, like phencyclidines, NSAID, alpha-2 agonist, opioids and muscle relaxants ${ }^{3}$.
The present prospective, randomized, controlled clinical trial had been undertaken to evaluate the effects of Dexmedetomidine or Ketamine when used as an adjuvant to Lignocaine hydrochloride for intravenous regional anaesthesia for forearm $\&$ hand surgeries.

\section{Material and Method}

On approval from institutional ethical committee and obtaining written informed consent, present study was conducted on 90 patients of either sex belonging to ASA I and II between age group of 18 to 60 years. Patients were divided into three different groups. (Each group include 30 patients). Thorough preanaesthetic evaluation was carried out on the previous day of surgery \& patients were explained regarding the procedure \& VAS

Type of study: Prospective, Randomised controlled study

Exclusion Criteria:

Following patients were excluded from the present study.

- Patients refusal \& Prolonged surgery $(>2 \mathrm{hr})$

- PVD, Reynaud's disease

- Cardiac arrhythmia, Uncontrolled hypertension

- H/o Convulsion, H/o chronic pain \& Opioid dependence.

- Neurological disease 


\section{International Journal of Science and Research (IJSR) \\ ISSN (Online): 2319-7064}

Index Copernicus Value (2013): 6.14 | Impact Factor (2015): 6.391

- Hemoglobinopathies \& coagulation disorders.

\section{Methodology}

1) Preloading was done with an infusion of Ringer's lactate $10-15 \mathrm{ml} / \mathrm{kg}$.

2) Premedication: Inj. Glycopyrrolate $5 \mu \mathrm{g} / \mathrm{kg}$ and Inj.Midazolam 40-70 $\mu \mathrm{g} / \mathrm{kg}$ IM $45 \mathrm{~min}$ before surgery.

3) Patients were randomly divided into 3 groups of 30 patients each:

a) Group(L): Inj. Lignocaine HCL $0.5 \%=$ total volume $40 \mathrm{ml}$

b) Group (LK): Inj. Lignocaine HCL $0.5 \%$ + Inj. Ketamine $0.5 \mathrm{mg} / \mathrm{kg}=$ total volume $40 \mathrm{ml}$

c) Group (LD): Inj. Lignocaine HCL 0.5\% + Inj. Dexmedetomidine $1 \mu \mathrm{g} / \mathrm{kg}=$ total volume $40 \mathrm{ml}$

4) Pulse rate, blood pressure, respiratory rate, $\mathrm{SpO} 2, \mathrm{ECG}$ and VAS were recorded before anaesthesia and considered as baseline parameter.

5) An intravenous cannula -22 gauge was inserted as distally as possible on the dorsum of the operative hand.

6) The operative arm was elevated for $5 \mathrm{~min}$ and exsanguinated.

7) A double pneumatic tourniquet was applied on operating limb \& proximal one was inflated (tourniquet pressure $=$ systolic B.P. $+100 \mathrm{mmhg}$ ).

8) Loss of circulation in operative arm was verified by inspection, absence of radial pulse and loss of the pulse oxymetry tracing in the ipsilateral index finger after tourniquet inflation.

9) According to study group assigned, drugs were injected.

10)After sensory and motor block onset, the distal tourniquet was inflated and the proximal one was carefully deflated.

11)The tourniquet kept inflated for at least 20-25 min. after the injection of local anaesthetic even if the surgical procedure was much shorter to prevent LA toxicity \& after completion of surgery, the tourniquet was deflated by a cyclic deflation technique.

12)Maximal allowable tourniquet inflation time was up to $120 \mathrm{~min}$.

\section{Assessment:}

I. Intraoperative Monitoring:

- Pulse, B.P., Spo2, E.C.G, tourniquet pressure, sedation score were noted at every $10 \mathrm{~min}$ interval till the end of surgery.

- Sensory blockade was evaluated by pin prick method with a 22 gauge short -bevelled needle after $20 \mathrm{sec}$ of drugs administered at every $20 \mathrm{sec}$. interval till the lack of pain sensation.

- Motor blockade was assessed at every 1 min. Interval till the patient was not able to produce movement of any fingers.

- Intraoperatively tourniquet pain was measured by VAS (Visual Analogue Scale) and Inj. Fentanyl $1 \mu \mathrm{g} / \mathrm{kg}$ IV was administered if $\mathrm{VAS} \geq 3$

- Total duration of surgery and tourniquet inflation time was noted.

\section{Postoperative Monitoring}

Duration of postoperative analgesia as the time between tourniquet deflation to first complain of pain at incision site was considered.

- In the postoperative period, Inj. Diclofenac Sodium 1.5 $\mathrm{mg} / \mathrm{kg}$ I.M. was used as rescue analgesic. (VAS >4) \& time of first rescue analgesic was noted.

- Side effects of study drugs like hypotension ( $<20 \%$ of baseline BP), bradycardia (<60/min.), tachycardia (>100/min.), nystagmus, delirium, local anesthetic toxicity like dizziness, nausea, vomiting, tinnitus, perioral tingling, muscle twitching, loss of consciousness, convulsions were noted.

- Quality of anaesthesia was rated by patient satisfaction score after completion of surgery.

\section{Statistical analysis}

In the study, results were presented as mean \pm SD (standard deviation). ANOVA test was applied for quantitative data and chi-square test for qualitative data.

\section{Result}

A total of 72 patients were enrolled in the study $(n=24$ in each group). The mean age and duration of surgery were not different between groups $(P>0.05)$. All the patients operated during the study period were from either sex. Among the patients, none was excluded from the study because of technical failure. The patients in all group weighed were comparable. Duration of surgery were similar in all the groups [Table 1]. Types of surgery performed are depicted in [table 2]. No patient needed treatment for hypotension or bradycardia.

Type of Surgery

\begin{tabular}{|c|c|c|c|c|}
\hline Type of surgery & Group L & Group LD & Group LK & Total \\
\hline \# finger & 8 & 2 & 3 & 13 \\
\hline \# radius & 6 & 7 & 10 & 23 \\
\hline \# ulna & 1 & 5 & 6 & 12 \\
\hline \# radius + Ulna & 3 & 10 & 8 & 21 \\
\hline Wrist ganglion & 5 & 2 & 2 & 9 \\
\hline CTS release & 3 & 4 & 1 & 8 \\
\hline Implant removal & 4 & 0 & 0 & 4 \\
\hline Total & 30 & 30 & 30 & 90 \\
\hline
\end{tabular}

Table 1: Patient characteristics and outcome measures

\begin{tabular}{|c|c|c|c|c|}
\hline & Group L & Group LD & Group LK & P value \\
\hline Age(in years) & $32.16 \pm$ & $35.63 \pm$ & $34.00 \pm$ & $>0.05$ \\
& 12.12 & 10.83 & 11.17 & \\
\hline Duration of & $39.00 \pm$ & $46.33 \pm$ & $48.66 \pm$ & $>0.05$ \\
surgery(mins) & 14.64 & 16.86 & 18.14 & \\
\hline Onset of sensory & $393 \pm 7$ & $258 \pm 10$ & $78 \pm 5$ & $<0.0001$ \\
block(sec.) & & & & \\
\hline Onset of motor & $17 \pm 1$ & $12 \pm 1$ & $8 \pm 1$ & $<0.0001$ \\
block(min.) & & & & \\
\hline Satisfaction score & $2.73 \pm 0.44$ & $2.83 \pm$ & $2.93 \pm$ & 0.118 \\
& & 0.37 & 0.25 & \\
\hline Total duration of & $5.61 \pm 2.22$ & 60.56 & $169 \pm 9$ & $\mathrm{P}<0.01$ \\
analgesia(min.) & & \pm 5.02 & & \\
\hline Total tourniquet & $55.83 \pm$ & $57.67 \pm$ & $58.67 \pm$ & $\mathrm{p}>0.05$ \\
time(min.) & 11.81 & 16.53 & 18.07 & \\
\hline
\end{tabular}

The onset of sensory and motor block was faster in Group LK as compared to other groups $(P<0.0001)$ although the 


\section{International Journal of Science and Research (IJSR) \\ ISSN (Online): 2319-7064 \\ Index Copernicus Value (2013): 6.14 | Impact Factor (2015): 6.391}

duration of analgesia, as seen by time to first analgesia demand by the patient, was more in patients in Group LD $(P$ $<0.0001)$. During intra operative period, from 10min. to end of surgery VAS was 0 in all groups. Thus, none of the patient required supplemental analgesia or anaesthesia during surgery. None of the patient developed tourniquet pain during surgery. At the end of surgery, VAS was $5.7 \pm$ 1.08 at $5.61 \pm 2.22$ min.(mean $\pm \mathrm{SD}$ ) in group L, $5.6 \pm 1.19$ at $60.56 \pm 5.02 \mathrm{~min}$. (mean $\pm \mathrm{SD}$ ) in group LK \& $4.0 \pm 0.53$ at $169 \pm 9$ min. (mean \pm SD) in Group LD rescue analgesia was administered. Thus, during postoperative period maximum analgesia was observed with Group LD $(169 \pm 9 \mathrm{~min}$.$) which was statistically highly significant$ $(\mathrm{p}<0.001)$.

Post recovery pain was similar in Group LK and LD but less than in Group L $(P<0.0001)$. Sedation score was highest in Group LD while lowest in Group L $(P<0.0001)$. Patients in Group LK were more satisfied than other groups in which the satisfaction scores were similar $(P<0.05)$. None patient developed any unpleasant effect in all groups. Patients were more satisfied in Group LK as compared to Group L or LD $(P<0.05)$

\section{Discussion}

IVRA technique is widely used for surgery on arms. IVRA is safe and problems are few. The advantages of IVRA are high indices of reliability, rapid onset of analgesia within 510 minutes and good muscular relaxation. The disadvantage of IVRA is the application of a tourniquet, which must remain inflated continuously throughout the procedure. The duration of surgery is limited by the time during which the arterial tourniquet could be kept safely inflated. Tourniquet pain, which is described as a dull and aching pain sensation, is a well-known limitation of IVRA. Skin compression, tourniquet size, and inflation pressure have been implicated as factors involved in tourniquet pain. Another drawback with this technique is the absence of postoperative analgesia. In several studies it was tried to find a local anesthesia mixture that allows relief from tourniquet pain and prolonged duration of analgesia after tourniquet release. Non-steroidal anti-inflammatory drugs, opioids, and combination of opioid and muscle relaxant have been used without demonstrating clear advantage.[2]

Ketamine, a phenyl-piperidine derivative, was first synthesized in the early 1960 s as an IV anesthetic agent. At subanesthetic doses, ketamine exerts a noncompetitive blockade of $N$-methyl aspartate (NMDA) receptors. NMDA receptors play a major role in synaptic plasticity and are specifically implicated in central nervous system facilitation of pain processing. NMDA receptor antagonists have been implicated in perioperative pain management. Ketamine also has local anesthetic qualities, which have been studied as a sole agent for IVRA.[7] In addition to spinal cord NMDA receptors, NMDA receptors have also been identified on peripheral unmyelinated sensory axons. This can explain why ketamine as an NMDA receptor antagonist was able to attenuate the tourniquet pain. Ketamine $0.5 \%$ and $0.3 \%$ produced adequate IVRA. Anesthesia was inadequate when a $0.2 \%$ concentration was used. Although $0.3 \%$ concentration provides complete sympathetic, sensory and motor blockade when injected into the isolated extremity. Unpleasant psychotomimetic effects after the release of the tourniquet limit the usefulness of this use of ketamine. [8,9] When ketamine is used with lignocaine $(0.5 \%)$ in a dose of 3 $\mathrm{mg} / \mathrm{kg}$ of body weight, duration of analgesia after release of tourniquet is longer, and the quality of analgesia is superior. The onset of analgesia and motor blockade remains similar and all patients suffered from disorientation and hallucinations. [8] In comparison to systemic administration, there is no selective benefit to adding ketamine to the IVRA inject.[10] Ketamine cannot be recommended as a sole agent for IVRA unless these unpleasant side effects are abolished or controlled by means of pharmacologic adjuvant.[11] When used in the doses of 0.1 to $0.5 \mathrm{mg} / \mathrm{kg}$ of body weight in IVRA no central nervous system symptoms have been observed.[12] Our study clearly demonstrated benefit of ketamine in IVRA when compared to a placebo. There was an early onset of sensory and motor block and good postoperative analgesia, although postoperative analgesia was longer in the dexmedetomidine group. No second cuff inflation was required in any patient denoting delay in onset of the tourniquet pain. Ketamine has well known hemodynamic effects (hypertension and tachycardia) but it failed to show any of these effects when given as an adjuvant in IVRA in our study. This could be due to the fact that the tourniquet was not deflated before $30 \mathrm{~min}$.

Clonidine has been shown to decrease tourniquet pain and intraoperative analgesic requirement in IVRA.[13] Dexmedetomidine is approximately eight times more selective toward the $\alpha 2$-adrenoceptors than clonidine.[5] Centrally active $\alpha$-adrenergic agonists exert powerful analgesic action that probably is transduced at several levels. Dexmedetomidine has been shown to enhance the local anesthetic action of lignocaine via $\alpha 2 \mathrm{~A}$ adrenoceptor.[14] Perioperative dexmedetomidine administration decreases the requirements for opioid or non-opioid analgesics both intra and postoperatively.[15] IV dexmedetomidine as a premedication has been effective before IVRA because it reduces patient anxiety, sympathoadrenal responses, and opioid analgesic requirements but it did not reduce tourniquet pain.[16,17] Addition of dexmedetomidine to prilocaine in IVRA decreases pain scores, improves anesthesia quality, decreases analgesic requirement, shortens sensory block onset time, and prolongs sensory block recovery time. [6,18] Addition of dexmedetomidine to lignocaine in IVRA also improves the quality of anesthesia and decreases the analgesic requirements but has no effect on the sensory and motor block onset and regression time.[6] Our study demonstrated that the addition of dexmedetomidine, in dose of one $\mathrm{mcg} / \mathrm{kg}$ of body weight, to lignocaine for IVRA not only improved quality of anesthesia and postoperative analgesia without causing significant side effects but also shortened the onset of sensory and motor block as compared to placebo. Dexmedetomidine administration produces abrupt hypertension and bradycardia until the central sympatholytic effect dominates, resulting in moderate decrease in both mean arterial pressure and heart rate from baseline.[19] In our study, no such hemodynamic changes were observed with use of dexmedetomidine in IVRA. IV dexmedetomidine is also known to exert a sedative effect, which was significantly higher than other groups in our study. 


\section{International Journal of Science and Research (IJSR) \\ ISSN (Online): 2319-7064}

Index Copernicus Value (2013): 6.14 | Impact Factor (2015): 6.391

Thus, adjuvant like Ketamine $(0.5 \mathrm{mg} / \mathrm{kg})$ or Dexmedetomidine $(1 \mu / \mathrm{kg})$ with $0.5 \%$ Lignocaine $(40 \mathrm{ml})$ gives better quality of anaesthesia $\&$ postoperative analgesia with no significant side effects in IVRA for forearm $\&$ hand surgeries.

We are very much thankful to Dr.Pragna Vachharajani (H.O.D. anesthesia dept. ) to guide and help us to carry out this study at SMIMER.

\section{References}

[1] Abhishek Gupta, Mamta M., Neeraj N. A comparative study of two different doses of Dexmedetomidine as adjuvant to Lignocaine in IVRA for upper limb surgeries. IJOSS.2014, 2: 53-62.

[2] Alok kumar, DK sharma, Barun Datta. Addition of ketamine or dexmedetomidine to lignocaine in IVRA: A randomized controlled study. JOACP.2012, 28:501-4.

[3] Bier A. On local anaesthesia with special reference to vein anaesthesia. Edinburgh Med J 1910; 5:103- 23.

[4] Dilek Memis, Alparslan Turan, Beyhan Karamanlıoglu, Zafer Pamukc, and Imran Kurt, Adding Dexmedetomidine to Lidocaine for Intravenous regional anesthesia. Anesth Analg 2004; 98:835-40.

[5] Durrani Z. Winnie A P, Sigmond EK, Burnett ML. Ketamine for intravenous regional anaesthesia. Anaesthesia and Analgesia 1989:68; 328-332.

[6] Elmetwaly K. F, Hegazy N A, Abdelmonem A. Does the use of ketamine or nitroglycerin as an adjuvant to lidocaine improve the quality of IVRA? Saudi J Anaesth 2010, 4(2):55-60.

[7] E. M. Brown et al., "Intravenous Regional Anesthesia (Bier Block): Review of 20 Years' Experience", Can. J. Anaesthesia, 1989, vol. 36, pp. 307-310.

[8] Gentili M, Bernard J-M, Bonnet F. Adding clonidine to lidocaine for intravenous regional anesthesia prevents tourniquet pain. Anesth Analg 1999; 88:1327-30.

[9] Haider H. S., Mahdi F. A.The combination effect of lidocaine, ketamine \& atracurium in IVRA.KCMJ 2013:9(2):61-63.

[10] Henderson, Cynthia L, Warriner, C. Brian, McEwen, James A, Merrick, Pamela M. (1997). "A North American survey of intravenous regional anesthesia". Anesthesia \& Analgesia (International Anesthesia Research Society) 85: 858-63.

[11] Holmes C McK. Intravenous regional anaesthesia: A useful method of producing analgesia of the limbs. Lancet 1963; 1: 245-247.

[12] Ivie C. S, Viscomi C. M, Adams D C. Clonidine as anadjunct to IVRA: A randomized, double-blind, placebo-controlled dose ranging study: LACP2011. 27(3):323-327.

[13] Maximilian W. B. Hartmannsgruber, David G. Silverman: Comparison of Ropivacaine $0.2 \%$ and Lidocaine $0.5 \%$ for Intravenous Regional Anesthesia in Volunteers, Anesth Analg 1999; 89: 727-31.

[14] Sukhani R, Garcia CJ, Munhall RJ, Winnie AP, Rodvold KA. Lidocaine disposition following intravenous regional anesthesia with different tourniquet deflation techniques. Anesth Analg 1989; 68:633-7.
[15] Yasser M N, Salwa H W. Lidocaine-tramadol versus lidocaine-dexmedetomidine for IVRA. Egyptian jon. of anaes. 2012:28, 37-42.

Volume 5 Issue 6, June 2016 www.ijsr.net 